\title{
Barriers and facilitators to uptake of systematic reviews by policy makers and health care managers: a scoping review
}

\author{
Andrea C. Tricco ${ }^{1,2}$, Roberta Cardoso' ${ }^{1}$, Sonia M. Thomas' ${ }^{1}$, Sanober Motiwala', Shannon Sullivan ${ }^{1}$, \\ Michael R. Kealey ${ }^{1,3}$, Brenda Hemmelgarn ${ }^{4}$, Mathieu Ouimet ${ }^{5}$, Michael P. Hillmer ${ }^{6,7}$, Laure Perrier ${ }^{6}$, \\ Sasha Shepperd ${ }^{8}$ and Sharon E. Straus ${ }^{1,9^{*}}$
}

\begin{abstract}
Background: We completed a scoping review on the barriers and facilitators to use of systematic reviews by health care managers and policy makers, including consideration of format and content, to develop recommendations for systematic review authors and to inform research efforts to develop and test formats for systematic reviews that may optimise their uptake.

Methods: We used the Arksey and O'Malley approach for our scoping review. Electronic databases (e.g., MEDLINE, EMBASE, Psyclnfo) were searched from inception until September 2014. Any study that identified barriers or facilitators (including format and content features) to uptake of systematic reviews by health care managers and policy makers/analysts was eligible for inclusion. Two reviewers independently screened the literature results and abstracted data from the relevant studies. The identified barriers and facilitators were charted using a barriers and facilitators taxonomy for implementing clinical practice guidelines by clinicians.

Results: We identified useful information for authors of systematic reviews to inform their preparation of reviews including providing one-page summaries with key messages, tailored to the relevant audience. Moreover, partnerships between researchers and policy makers/managers to facilitate the conduct and use of systematic reviews should be considered to enhance relevance of reviews and thereby influence uptake.
\end{abstract}

Conclusions: Systematic review authors can consider our results when publishing their systematic reviews. These strategies should be rigorously evaluated to determine impact on use of reviews in decision-making.

Keywords: Systematic reviews, Determinants of knowledge uptake

\section{Background}

Knowledge syntheses are comprehensive and reproducible evidence reviews that summarise all relevant studies on a question [1]. They can include traditional systematic reviews and scoping reviews, amongst others. Knowledge translation (KT) focusing on the results of individual studies may be misleading due to bias in their conduct or random variations in findings [2]. Knowledge syntheses that

\footnotetext{
*Correspondence: sharon.straus@utoronto.ca

'Knowledge Translation Program, Li Ka Shing Knowledge Institute, St.

Michael's Hospital, 209 Victoria Street, East Building, Toronto, ON M5B 1W8,

Canada

${ }^{9}$ Department of Geriatric Medicine, University of Toronto, 27 Kings College

Circle, Toronto, ON M5S 1A1, Canada

Full list of author information is available at the end of the article
}

interpret the results of individual studies within the context of global evidence should be considered as the foundational unit of $\mathrm{KT}$, as they interpret the results of individual studies within the context of the totality of evidence and are less susceptible to bias than single studies [3]. Knowledge syntheses, such as systematic reviews, provide the evidence base for implementation vehicles, such as patient decision aids and clinical decision aids clinical practice guidelines and policy [3]. For example, our research team conducts knowledge syntheses for the nationally funded Drug Safety and Effectiveness Network whereby we complete knowledge synthesis to answer questions posed by our provincial and national policy makers $[4,5]$. 
There have been several models or classifications of evidence (or knowledge) use [6-13]. Larsen described conceptual and behavioural knowledge use [7]. Conceptual knowledge use refers to using knowledge to change the way users think about issues. Instrumental knowledge use refers to changes in action as a result of knowledge use. Dunn categorised knowledge use by describing that it could be done by the individual or a collective [8]. Weiss also described several frameworks for knowledge use, including the problem solving model, which she described as the direct application of the results of a study to a decision [9]. She further described this as using knowledge as "ammunition" [9]. Beyer and Trice labelled this type of knowledge use as symbolic, which they added to Larsen's framework [10]. Symbolic use involves the use of research as a political or persuasive tool. Estabrooks described a similar framework for knowledge use including direct, indirect, and persuasive research utilisation, where these terms are analogous to instrumental, conceptual, and symbolic knowledge use, respectively [11].

We find it useful to consider conceptual, instrumental and persuasive knowledge use $[6,12]$. Conceptual use of knowledge implies changes in knowledge, understanding, or attitudes. Research could change thinking and inform decision-making but not change behaviour. Instrumental knowledge use is the concrete application of knowledge and describes changes in behaviour, for example [6]. Evidence can be translated into a usable form, such as a care pathway, guideline, or policy, and is used in making a specific decision. Persuasive knowledge use is also called strategic or symbolic knowledge use and refers to research being used as a political or persuasive tool. It relates to the use of knowledge to attain specific power or profit goals (i.e. knowledge as ammunition) $[6,12]$.

Use of evidence by policy makers and managers can include any of these approaches. Oliver and colleagues have argued that the concept of knowledge use is further complicated in the policy context because research evidence is just one form of knowledge that informs decisionmaking. They also pose that researchers need to understand what influences and constitutes policy to better understand what evidence is required and how it can be used [13].

Despite advances in the conduct and reporting of systematic reviews and recognition of their importance in health care decision-making, current evidence suggests that they are infrequently used by health care managers and policy makers $[14,15]$. Failure of health systems to optimally use high-quality research evidence results in inefficiencies, reduced quantity and quality of life, and lost productivity $[16,17]$. As just one example of this issue, glucose self-testing by older patients with diabetes who use oral hypoglycemic agents has been identified as unnecessary and potentially harmful to patients in systematic reviews [18]. However, financial reimbursement for glucose test strips for these patients continues in many countries, costing just one province in Canada $\$ 40$ million per year [19].

We previously conducted a knowledge synthesis [20] to identify interventions to encourage use of systematic reviews by health policy makers and health care managers and identified four articles. Three of these articles described one study in which five systematic reviews were mailed to public health officials and followed up with surveys [21-23]. The authors found that 23 to $63 \%$ of survey respondents reported using the systematic reviews to inform policy making decisions. The fourth study was a randomised trial of tailored messages combined with access to a registry of systematic reviews and showed a significant effect on policies made in the area of health body weight promotion by health departments [24]. In more recent systematic reviews [25, 26], no additional studies were identified that assessed interventions to increase uptake of systematic reviews by health care managers and policy makers.

Given that systematic reviews are less susceptible to bias than a single primary study or the opinions of experts, it is not clear why they are not used routinely in decision-making. Two systematic reviews of barriers and facilitators to the use of systematic reviews by any type of decision-maker (e.g. clinicians, patients, managers) identified many factors that contribute to paucity of use including lack of relevance of the questions the reviews are addressing, lack of contextualisation of findings, unwieldy size of the report, and poor presentation format; these factors can be considered intrinsic to the systematic review $[25,27]$. The format of systematic reviews has been a key factor identified to influence their use by policy makers and managers [28]. While attention has been paid to enhance the quality of systematic reviews, relatively little attention has been paid to their format. For example, health care managers and policy makers would benefit from highlighting information that is relevant for their decisions including contextual factors affecting local applicability and information about costs [27]. And, because reporting of systematic reviews tends to focus on methodological rigour rather than context, they often do not provide crucial information for decision-makers. Other barriers to use of reviews by health care managers and policy makers include factors extrinsic to the review, such as lack of access and time to seek and acquire systematic reviews and lack of skills to appraise and apply the evidence [27, 29].

Surveys and interviews with policy makers and managers have identified the importance of increasing the usability of systematic reviews in decision-making [30, 31]. Understanding how to make systematic reviews more usable requires consideration of barriers and facilitators to their use, as well as of their format and content. As such, we 
completed a scoping review on the barriers and facilitators to use of systematic reviews including consideration of format and content by health care managers and policy makers to develop recommendations for systematic review authors and to inform research efforts to develop and test formats for systematic reviews that may optimise uptake. This project arose directly from our decision-maker partners, for whom we conduct knowledge syntheses. This review is part of a multi-phase project to develop and testing a format for a systematic review to optimise use.

\section{Methods}

We conducted a scoping review [32] using guidance from the Joanna Briggs Methods Manual for Scoping Reviews [33]. A protocol was prepared and revised using input from our key stakeholders. Although the PRISMA Statement has not been modified for scoping reviews, we used it to guide reporting [34].

\section{Data sources and search}

We searched the following electronic databases from inception until week 3 of September 2014: MEDLINE, EMBASE, PsycInfo, The Cochrane Database of Systematic Reviews, Cochrane Central Register of Controlled Trials, CINAHL, and LISA (Library and Information Science Abstracts). The literature searches for the previous reviews [20,26] were peer-reviewed by an information scientist and modified as necessary. The full literature search for MEDLINE is available in Additional file 1, and the other database searches are available from the corresponding author upon request. The search strategy was not limited by study design or language of dissemination. The grey literature was searched using Google after identifying key websites (such as websites of funding agencies and health care provider organisations in Canada, the USA, and the UK that fund or conduct systematic reviews). We supplemented the literature search by scanning references of included articles and relevant, published systematic reviews [20, 25-27, 29]. We also conducted a forward citation search in the Web of Science whereby we used the included studies to identify other potentially relevant studies. The results of the literature search were imported into Synthesi.SR [35], which was used for screening by the review team.

\section{Study selection: inclusion criteria}

Eligible studies included health care managers (defined as an individual in a managerial or supervisory role in a health care organisation with management and supervisory mandates, including public health officials) or policy makers/analysts (defined as an individual (non-elected) at some level of government; they may have some responsibility for analysing data and making recommendations to others and may include regional, provincial, or federal representation) as participants. The focus of the review was on policy/management decision-making; however, clinical decision-making articles were included if policy decision-making was also mentioned and these data could be abstracted. Often the policy articles considered clinical decision-making as well, given that this is often a downstream consideration. For example, if the policy makers felt that clinicians would not implement the evidence, this would be eligible for inclusion. Studies that identified barriers or facilitators (including format and content features) to uptake of systematic reviews by health care managers and policy makers/analysts were eligible for inclusion. All study designs including qualitative or quantitative methodologies where there was a description of the barriers or facilitators to use of evidence from systematic reviews by the relevant end-user groups were eligible. Specifically, we included systematic reviews, experimental (randomised controlled trials, quasirandomised controlled trials, non-randomised controlled clinical trials), quasi-experimental (controlled before after studies, interrupted time series), observational (cohort, case control, cross-sectional), and qualitative studies. If more than one publication described a single study presenting the same data, we included the most recent. Studies conducted in any setting or country and those published in any language were eligible for inclusion.

\section{Study selection: screening}

To ensure reliability, a calibration exercise with reviewers was conducted prior to commencing screening. Using the eligibility criteria, a random sample of $10 \%$ of citations from the search were screened independently by all reviewers. Screening only began when percent agreement was $>90 \%$ across the review team. A similar calibration exercise was completed prior to screening full-text articles for inclusion. Subsequently, two reviewers independently reviewed titles and abstracts and full-text articles for inclusion. Conflicts were resolved through discussion.

\section{Data abstraction}

Two reviewers independently reviewed each full-text article and extracted relevant data. Data were extracted on study design, participants, country, barriers, and facilitators to use of the systematic review. Differences in abstraction were resolved by discussion. We did not assess risk of bias of individual studies because our aim was to map the evidence, as is consistent with the proposed scoping review methodology [32, 33].

\section{Data charting and collation}

The barriers and facilitators were charted using a taxonomy of barriers and facilitators to implementation of clinical practice guidelines by clinicians [36]. This taxonomy was expanded to include attributes of the 
systematic review, specifically its format and content, and was reviewed by a health care manager to ensure face validity. The taxonomy was based on a systematic review of barriers and facilitators to evidence use by clinicians as no similar review was available explicitly for policy makers and managers at the time we completed our review. We shared the taxonomy with our decisionmaker partners to assess for face validity and no additional categories were identified. Two reviewers reviewed each article and identified the unit of text relevant to each of these factors using a coding scheme they developed. Qualitative analysis was conducted using NVivo 10 [37]. Codes were aggregated by themes, centred on whether the barriers/facilitators influenced participants' attitudes towards; knowledge of; skills in seeking, appraising or using; or use of systematic reviews in decision-making. Discrepancies in coding were discussed by the team to achieve consensus.

\section{Consultation}

Team members (including representatives from the health care managers and policy makers/analysts from the Ontario Ministry of Health and Long-term Care) were consulted at various stages of the scoping review to provide input on the search, data abstraction, and interpretation of the results.

\section{Results}

\section{Literature search}

A total of 6635 titles and abstracts and 201 full-text articles was assessed for eligibility. Subsequently, 19 studies reported in 21 publications fulfilled the eligibility criteria and were included [21-24, 30, 31, 38-52]. The reasons for excluding full-text articles are provided in Fig. 1.

\section{Characteristics of the included articles}

All but one of the studies was published after 2000. Authors of the papers were commonly from Canada, Australia, and the UK. Nineteen of the publications were qualitative studies, 1 study was quantitative and described the impact of an intervention to facilitate use of systematic reviews, and 1 was a systematic review. A description of included studies is provided in Table 1.

\section{Barriers to use of systematic reviews}

Barriers to the use of systematic reviews are presented in Table 2. We have also presented the results per study identified and present this in Additional file 2.

\section{Attitudes}

Factors limiting the use of systematic reviews through an affective component were considered as those barriers that affected attitudes towards the use of systematic reviews [36]. Lack of agreement with the usefulness of systematic reviews in general and lack of agreement with results of specific systematic reviews were identified as such barriers [21, 44, 50]. With regard to the former, participants believed that systematic reviews may challenge their autonomy in decision-making because the evidence in the review would dictate their decisions and this was perceived to be a barrier to their use. Lack of outcome expectancy was also a barrier to use whereby participants believed that decisions based on systematic reviews would not lead to the desired outcome because they did not believe the causal inference implied by the results of the review [45]. Lack of motivation to change or resistance to change was a barrier to use of systematic reviews [51]. Barriers related to lack of agreement with results of specific systematic reviews were also noted and included features such as participants' lack of agreement with the evidence interpretation, their lack of confidence in the authors of the review, or their belief that the results of the review are not valid [21].

\section{Knowledge}

Factors limiting adherence through a cognitive component were considered knowledge barriers to use of systematic reviews [36]. For example, participants reported the lack of awareness or lack of familiarity with a systematic review as influencing use. Particular challenges related to this factor included the tremendous volume of information required for participants to stay abreast of in relevant areas, the lack of knowledge on how to access relevant systematic reviews, and the lack of awareness of the importance of systematic reviews [24, 43, 44].

\section{Skills}

Factors limiting adherence to systematic review evidence through a lack of ability were considered barriers related to skills [36]. Participants reported the lack of skills to find, assess, interpret, or use systematic reviews in decision-making $[44,47,52]$. Additional elements included the lack of ability to reconcile patient preferences with recommendations.

\section{Behaviour}

Several behavioural barriers to use of systematic reviews were reported, and these focused on external barriers to their use, including patient and clinician factors. For example, patient and clinician resistance to implementing the evidence outlined in the systematic review may lead to policy makers and managers being reluctant to use the evidence. Participants also reported factors intrinsic to the systematic review as barriers to their use, including the presence of contradictory results from different systematic reviews or difficulty accessing reviews and in particular, difficulty identifying their key messages quickly when they are needed for decision- 


\section{FORMATTING SCOPING REVIEW - Flow diagram}
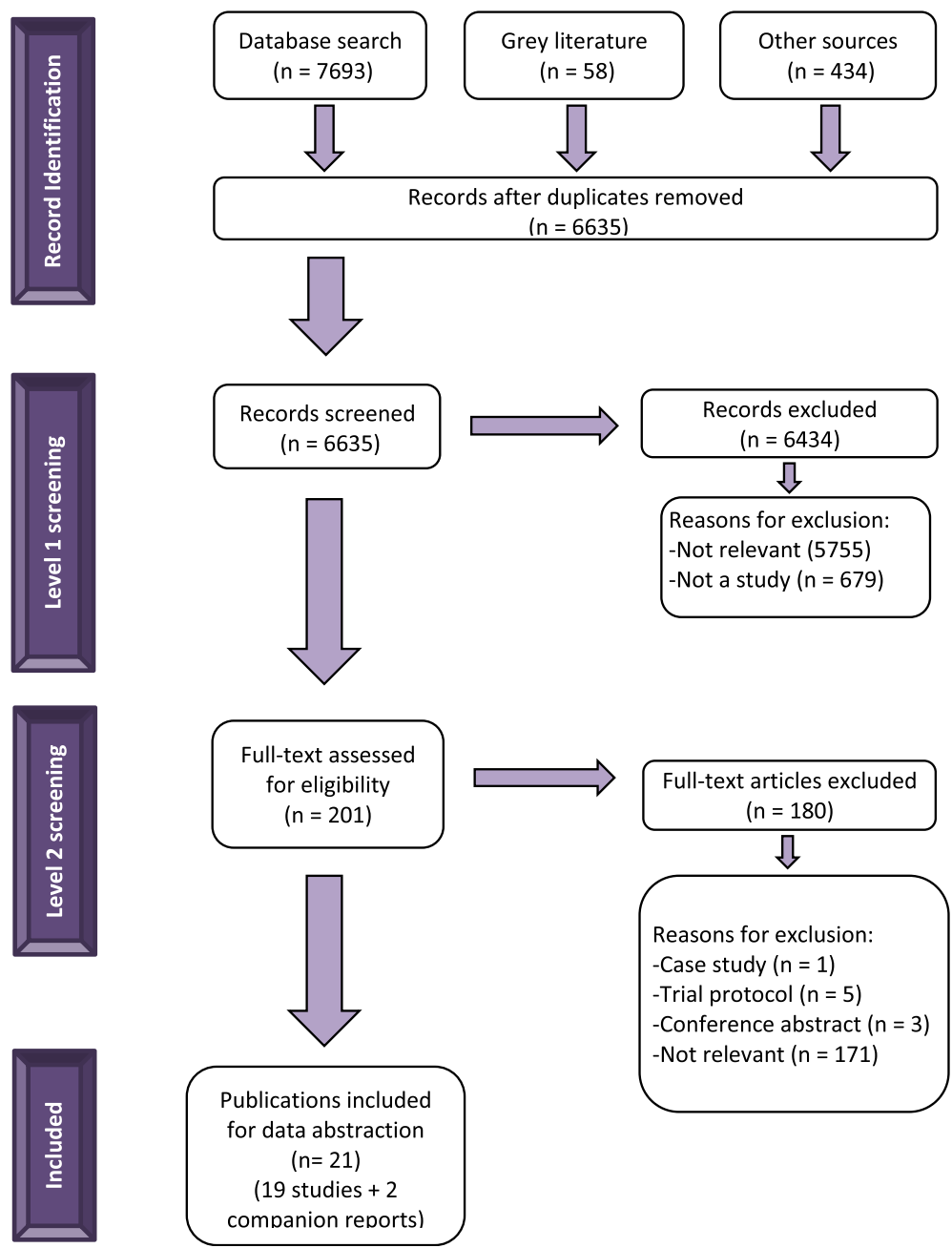

Publications included

$(n=21)$

(19 studies +2

Fig. 1 Study flow diagram

making [39, 44, 47]. Extrinsic or environmental barriers were identified including lack of time and organisational constraints, which prevent the individual from implementing the review. In one of the intervention studies that were included, lack of time and availability of relevant systematic reviews were identified as barriers to use in decision-making by public health officials [21, 42, 44].

\section{Facilitators to use of systematic reviews}

Facilitators to the use of systematic reviews are presented in Table 3.

\section{Attitudes}

Participants identified that agreement with the usefulness of systematic reviews, belief in their relevance, and their applicability to policy facilitated their use. Participants perceived systematic reviews were useful if they had confidence in the review authors [47, 52]. Enthusiasm and motivation to change were facilitators for use of systematic reviews; in particular, if important and relevant reviews could be provided to policy makers at key points in decision-making, this was perceived to be influential in their further use $[23,47,51]$.

\section{Knowledge}

Familiarity or awareness of systematic reviews were potential facilitators of their use. In particular, knowledge of their importance relative to single primary studies [31].

\section{Skills}

Participants reported that skills in seeking, appraising, and interpreting systematic reviews facilitated their use $[22,23,30]$. For example, training in basic searching skills was identified as a facilitator [52]. 
Table 1 Study Characteristics of Included Studies

\begin{tabular}{|c|c|c|c|c|c|}
\hline Studies [reference] & Country & Study design & Setting & $\begin{array}{l}\text { Type of end user or } \\
\text { participant }\end{array}$ & $\begin{array}{l}\text { Number of end users } \\
\text { or participants }\end{array}$ \\
\hline Albert 2007 [38] & Mali & Qualitative study & $\begin{array}{l}\text { National government: } \\
\text { pharmaceutical decision- } \\
\text { making group }\end{array}$ & Health policy maker & 19 \\
\hline Armstrong 2012 [39] & Australia & Qualitative study & Health related organisations & $\begin{array}{l}\text { National stakeholders } \\
\text { of relevance to } \\
\text { employment and } \\
\text { health, advocacy, } \\
\text { member organisation } \\
\text { for a workforce or } \\
\text { national policy }\end{array}$ & 9 \\
\hline Atack 2010 [40] & Canada & Qualitative study & $\begin{array}{l}\text { Different health care settings } \\
\text { (research hospital, community } \\
\text { hospital, community health } \\
\text { centre, long-term care facility, } \\
\text { district/regional health } \\
\text { authority, government } \\
\text { ministry/department, } \\
\text { academic health science } \\
\text { centre, others) }\end{array}$ & Health care manager & $\begin{array}{l}42 \text { for Technology } \\
\text { Acceptance Model } \\
\text { survey (TAMS) and } \\
12 \text { for interviews }\end{array}$ \\
\hline Campbell 2009 [42] & Australia & Qualitative study & $\begin{array}{l}\text { Public health and health } \\
\text { service government }\end{array}$ & $\begin{array}{l}\text { Health policy maker } \\
\text { and researcher }\end{array}$ & $\begin{array}{l}38 \text { policy makers/41 } \\
\text { researchers }\end{array}$ \\
\hline Campbell 2011[41] & Australia & Qualitative study & $\begin{array}{l}\text { Independent research } \\
\text { organisations and Department } \\
\text { of Health }\end{array}$ & $\begin{array}{l}\text { Health policy maker } \\
\text { and researcher }\end{array}$ & $\begin{array}{l}8 \text { policy makers/11 } \\
\text { researchers }\end{array}$ \\
\hline Ciliska 1999 [21] & Canada & Qualitative study & Public health organisations & $\begin{array}{l}\text { Health care managers } \\
\text { and total, } 277 \text { were } \\
\text { eligible, } 242 \text { participated } \\
\text { in the first survey; } 225 \\
\text { participated in the } \\
\text { second survey }\end{array}$ & \\
\hline Dobbins 2001a (CR to Ciliska 1999) [22] & Canada & Qualitative study & & & \\
\hline Dobbins 2001b (CR of Ciliska 1999) [23] & Canada & Qualitative study & & & \\
\hline Dobbins 2004 [30] & Canada & Qualitative study & $\begin{array}{l}\text { Public health/health } \\
\text { promotion, government }\end{array}$ & $\begin{array}{l}\text { Health care managers } \\
\text { and policy makers }\end{array}$ & 46 \\
\hline Dobbins 2004 [31] & Canada & Qualitative study & $\begin{array}{l}\text { Public health (programme } \\
\text { managers, directors, } \\
\text { epidemiologists, medical } \\
\text { officers of health, provincial } \\
\text { consultants, local board of } \\
\text { health members) }\end{array}$ & $\begin{array}{l}\text { Health care } \\
\text { managers and } \\
\text { policymakers }\end{array}$ & 51 participants \\
\hline Dobbins 2007 [43] & Canada & Qualitative study & $\begin{array}{l}\text { Public health decision-makers: } \\
\text { managers, directors, medical } \\
\text { officers }\end{array}$ & $\begin{array}{l}\text { Health care managers } \\
\text { and policy makers }\end{array}$ & 16 \\
\hline
\end{tabular}


Table 1 Study Characteristics of Included Studies (Continued)

Dobbins 2009a [24]

Jewell 2008 [44]

Lavis 2005 [45]

Packer 2000 [52]

England

Qualitative study

\section{$\mathrm{RCT}$}

Qualitative study

\section{Australia}

Norway, Argentina, China, Colombia, South Africa, and Uganda

Shepperd 2013 [48]

England

Qualitative study

Canada

Canada, England and Wales, Qualitative study

Finland, Germany, Italy,

the Netherlands, Norway,

Scotland, and Spain,

Cameroon, Ethiopia,

Uganda, and South Africa

Yousefi-Nooraie 2009 [51]

\section{Qualitative study}

Qualitative study

Iran
Systematic review and qualitative study health care managers and

Capacity building workshop policy makers, interviews of managers, policy makers, website review

5 health authorities

Public health departments

Health care manager

108

Conference attendees

Health policy maker

28 (11-public health 15-legislators;

$$
\text { 2-both) }
$$

Health care managers $\quad 17$ studies and 29 and policy makers participants

participants

Health policy makers:

health authority

contacts including

public health

consultants, public

health specialist

registrars, a research

analyst, and a public

health nurse

\section{Drug policy units}

Health policy maker

Health care managers

National or international

health service or policy-

related work in health

and policy makers

insurance programmes,

hospitals, or aid organisations

Regional health authorities

Clinicians and

Commissioners

(including 2 general

practice commissioners,

3 pharmacists, 6 public

health consultants,

and 4 health care

managers)

Provincial health authority Health care managers

and policy makers

National policy organisations

Health care managers

and policy makers

23 clinicians; 15 commissioners $(2$

general practice

commissioners,

3 pharma, 6

public health

consults, 4 managers)

13 participants

112 respondents

Health care managers

131 participants 
Table 2 Barriers to use of systematic reviews by policy makers and health care managers

\begin{tabular}{l} 
Attitudes \\
\hline Lack of agreement \\
Limited quantity of research \\
on topics of importance to \\
them, e.g. economic impact, \\
emerging technologies \\
[21, 44, 50] \\
Systematic reviews do not \\
necessarily frame the existing \\
evidence in terms of their \\
policy applications [44]
\end{tabular}

Lack of or unknown credibility of authors of the research [21]

Ethical disagreement [21]

Research information not valued at community level [21]

Policy decisions are made based on other factors like cost and equity considerations, particularly if evidence base is frail [52]

Mismatch between the type of content offered and their information needs [47]

$\begin{array}{lll}\text { Lack of outcome } & \text { Inertia of } & \text { Lack of awareness/ } \\ \text { expectancy } & \begin{array}{l}\text { previous or } \\ \text { actual practice/ } \\ \text { lack of motivation }\end{array} & \text { familiarity } \\ \text { Avoid providing } & \text { Lack of motivation } & \text { Administrators' }\end{array}$
to use reviews will limited recommendations require changing understanding of for action based policy makers' the function of on SR; do not SRs [44] believe in causal linkage [45] attitudes [51]

Information overload The health agency staff had not leads to lack of been taught "to continue to use awareness of a research to inform their decisions, particular systematic to inform their practice. They review $[24,43] \quad$ therefore made decisions based on "common sense", "gut level", "standards of practice", and comparative convenience and awareness of available data, rather than based on systematic reviews of research." [44, 52]

No policy makers mentioned having utilised information from systematic reviews, and most seemed unaware of their existence [38] Lack features that would make them easier for government officials to evaluate. For example the quality of studies is often difficult for non-experts to interpret because the explanation of research methods is long and complicated [44]

Appraising and synthesising the evidence was seen as an even bigger challenge [40]

Difficult to understand by people not trained in evidence-based medicine $[21,47]$

Words like "sample size" and "relative risk" would be difficult to interpret [47]

Lack of expertise in evaluating SRs [44]
Behaviour

SRs/intrinsic factors

Extrinsic factors

The review itself did not appear to be user-friendly due to in accessible language and dense Policy inconsistency within health care system (differing interests, layout [39] performance based incentives) [48]

Accessibility: within a systematic Attacks on an evidence-based review, have difficulty identifying approach. Several officials also key messages [44] discussed instances in which the discussed instances in which the
whole notion of evidence-based whole notion of evidence-based
health care had come under direc health care had come under direct companies, sometimes in collabor ation with advocacy groups, some of which hid their involvement with industry [44].

Concepts presented in tables, Accessibility. Even when evidence including those that showed the is available, policymakers may GRADE assessment and different have problems obtaining it [44] levels of risk, were not clear [47]

Tables running over 2 pages were cumbersome to read [47] Lack of availability of research results [21]

Abbreviations caused confusion [47]

Lack of resources to implement research [21]

Use of jargon and/or unfamiliar vocabulary [47]

Policy climate-provincial/regiona not conducive to use [21]

Numbers in the text and those Lack of timely completion of in the tables do not correspond review [21] precisely [47] 
Table 2 Barriers to use of systematic reviews by policy makers and health care managers (Continued)

\begin{tabular}{|c|c|c|}
\hline $\begin{array}{l}\text { Translating evidence to the } \\
\text { local context (including sub } \\
\text { groups of patients): individuals } \\
\text { frequently had to make } \\
\text { independent decisions about } \\
\text { how to relate evidence to } \\
\text { the needs of their local } \\
\text { context, discuss and debate } \\
\text { the evidence with local } \\
\text { stakeholders and take } \\
\text { decisions about its use } \\
\text { in practice [48] }\end{array}$ & & $\begin{array}{l}\text { Current practice patterns lead } \\
\text { policy makers and managers } \\
\text { reluctant to use reviews [21] }\end{array}$ \\
\hline \multirow{6}{*}{$\begin{array}{l}\text { Policymakers expected } \\
\text { content lying outside } \\
\text { the scope of a review: } \\
\text { recommendations, outcome } \\
\text { measurements not usually } \\
\text { included in a review, detailed } \\
\text { information about local } \\
\text { applicability or costs, and } \\
\text { a broader framing of the } \\
\text { research enquiry [47] }\end{array}$} & $\begin{array}{l}\text { Wanted a shorter, clearer } \\
\text { presentation [47] }\end{array}$ & $\begin{array}{l}\text { Cost of retrieving information } \\
\text { prohibitive [21] }\end{array}$ \\
\hline & $\begin{array}{l}\text { Reviews covered issues at a } \\
\text { more complex level than } \\
\text { required [52] }\end{array}$ & $\begin{array}{l}\text { Insufficient authority to implement } \\
\text { research results [21] }\end{array}$ \\
\hline & $\begin{array}{l}\text { Lack of detail on how to use } \\
\text { strategies, tools, processes that } \\
\text { would lead to successful } \\
\text { integration (i.e. guidance on } \\
\text { breaking down systems barriers } \\
\text { or how to achieve integration in } \\
\text { the context of big, complex } \\
\text { system) [49] }\end{array}$ & $\begin{array}{l}\text { Policy makers had difficulty } \\
\text { finding brief research summaries } \\
\text { and systematic reviews when } \\
\text { they were needed (i.e. difficulty } \\
\text { accessing SRs) [42] }\end{array}$ \\
\hline & $\begin{array}{l}\text { Tended not to use the full } \\
\text { report instead referring to the } \\
\text { less dense, more accessible } \\
\text { articles [49] }\end{array}$ & $\begin{array}{l}\text { Limited time to find, retrieve, } \\
\text { read, and translate research } \\
{[21,24,47]}\end{array}$ \\
\hline & $\begin{array}{l}\text { Wanted a shorter, clearer } \\
\text { presentation [47] }\end{array}$ & $\begin{array}{l}\text { Research often published in } \\
\text { academic sources, poorly } \\
\text { accessible to policy makers, LMIC } \\
\text { policy makers have limited access } \\
\text { to subscription-based K or the } \\
\text { internet [47] }\end{array}$ \\
\hline & & $\begin{array}{l}\text { Lack of indexing local journals in } \\
\text { international databases, } \\
\text { harmonised reporting criteria, } \\
\text { editorial processes and presentation } \\
\text { of local journals, minimum }\end{array}$ \\
\hline
\end{tabular}
required [52]

Tended not to use the full

eport instead referring to the

articles [49]

Wanted a shorter, clearer

of local journals, minimum 
Table 2 Barriers to use of systematic reviews by policy makers and health care managers (Continued)

standards for reporting of research

for all local journals. Coverage and

searching quality of databases of

papers published in local language

needs improvement, single national

database for research registration,

technical and professional support

for current databases [51]

If department within

commissioning organisation is

not in a position of strength,

unlikely that evidence will be

used for decision-making [52]

Lack of time to find or discuss

evidence, usually need an

answer to a problem on the

same day [52]

Finding the evidence was

described as problematic. Several

fellows called for greater access

to systematic reviews; this was

a resource they wanted to see

augmented through the

desktop [40]

Policy makers' belief that searching,

accessing, and reviewing research

findings are highly time

consuming is perhaps a good

argument for the increased

production, promotion, and

dissemination of systematic

reviews [38]

Limited time to read full study

reports (of a SR) [43] 
Table 3 Facilitators to use of systematic reviews by policy makers and health care managers

\begin{tabular}{|c|c|}
\hline \\
\hline \multicolumn{2}{|l|}{$\frac{\text { Attitudes }}{\text { Agreement/usefulness }}$} \\
\hline $\begin{array}{l}\text { Stakeholders described } \\
\text { potential uses of the } \\
\text { review as being more } \\
\text { indirect (creating a } \\
\text { culture); for example, } \\
\text { for advocacy purposes } \\
\text { internally, to promote a } \\
\text { particular intervention } \\
\text { approach and to identify } \\
\text { gaps of where further } \\
\text { evaluation was needed } \\
{[39,41,42]}\end{array}$ & $\begin{array}{l}\text { Expecting to use the systematic } \\
\text { reviews in the future [23] }\end{array}$ \\
\hline $\begin{array}{l}\text { SRs to provide guidance } \\
\text { and suggestions for } \\
\text { implementation of findings, } \\
\text { not just reporting facts [43] }\end{array}$ & $\begin{array}{l}\text { Willingness of health care } \\
\text { providers to use systematic } \\
\text { reviews [51] }\end{array}$ \\
\hline $\begin{array}{l}\text { Most policy makers } r \\
\text { eported having needed } \\
\text { the data and reviews in } \\
\text { the past } 12 \text { months, having } \\
\text { commissioned research or } \\
\text { reviews during this period, } \\
\text { and having used evidence } \\
\text { to contribute to the } \\
\text { content of policy [42] }\end{array}$ & $\begin{array}{l}\text { Perception that reviews facilitate } \\
\text { critical appraisal of evidence } \\
\text { and are easy to use, information } \\
\text { about what works and clearly } \\
\text { articulated implications for policy } \\
\text { (costs, applicability, impacts on } \\
\text { equity) [47] }\end{array}$ \\
\hline $\begin{array}{l}\text { Respondents who expected } \\
\text { to use the reviews in the } \\
\text { future were more likely to } \\
\text { have used a review than } \\
\text { those who did not expect } \\
\text { to use the reviews [22] }\end{array}$ & $\begin{array}{l}\text { Presenting selected important } \\
\text { systematic reviews to policy } \\
\text { makers may change their } \\
\text { attitudes towards evidence- } \\
\text { based decision-making, presenting } \\
\text { successful/unsuccessful policies [51] }\end{array}$ \\
\hline
\end{tabular}

Awareness/familiarity Expertise/experience/training SRs/intrinsic factors

Extrinsic factors

Recognition of relative One's age [23]—younger,

importance of SR compared more likely to use

Delineating the effects for

a particular group with

Making decisions in collaboration

to other sources of

more focused subgroup

analyses in SRs [44]

with other community

studies (culture of evidence-

enhanced their usefulness

likelihood of using reviews [23]

based decision-making) [31]

Number of years since

graduation [23] - more

recent graduates more

likely to use

Providing training in basic search skills may increase use [52] reviews could overcome the barrier of limited critica appraisal skills [22] successful/unsuccessful policies [51]
Coming from credible

sources [47]
Perception that systematic

Providing information

about the benefits, harms

(or risks), and costs [45]

Concise statements about

lives or money can infuse

the political discussion

with a tone of rasiona

with a tone of rationality,
framing the trade-offs as

technical and straightforward

[44]. Providing information

[44]. Providing information

about the benefits, harms

Identify attributes of the

context in which the research

included in a systematic

review was conducted to

inform assessments of the

applicability of the review in

other contexts [45]. Concise

statements about lives or

money can infuse the political

discussion with a tone of

rationality, framing the trade-

offs as technical and

straightforward [44]. Providing

information about the

benefits, harms (or risks), and

costs [45]

Ongoing training in critica

appraisal of research

literature [23]

Add additional local value to any type of systematic review

by using language that is

locally applicable and by

engaging in discussions about

the implications of reviews

with the health care managers
Increasing the opportunities for

interaction and exchange

between policy makers and
researchers is key to promoting

researchers is key to promoting
the use of research evidence in policy [42]

One-to-one interaction with the researcher to discuss research findings [43]

Organisational research culture $[23,24]$ favouring use of research to inform decisionmaking
Fund production and updating of SRs with additional resources for health care managers and policy makers to interact and fund local adaptation process for SR [45] 
Table 3 Facilitators to use of systematic reviews by policy makers and health care managers (Continued)

and policy makers who could

potentially act on the reviews

take-home messages [45]

context in which the research

included in a systematic review

was conducted to inform

assessments of the applicability

of the review in other contexts

[45]. Concise statements about

lives or money can infuse the

political discussion with a ton

of rationality framing the trade

offs as technical and

straightforward [44]

Relevance to policy decisions [31] Most

policy makers reported having needed data

and reviews in the past

12 months, having

commissioned research

or reviews during this

period, and having used

evidence to contribute

to the content of

policy [42]

Reassurance that no

reviews have been

missed [52]. Respondents

who expected to use the

reviews in the future

were more likely to

have used a review

than those who did

not expect to use the

reviews [22]
Opportunities for training and education on systematic

reviews (definition, significance, appraisal) [30] Ongoing training in critical appraisal of research iterature [23]

Ensure SRs are included in a one-stop-shop that provides quality-appraised reviews 45]. Add additional

local value to any type of systematic review by using

language that is locally applicable and by engaging in discussions about the implications of reviews with the health care managers and policy makers who could potentially act on the reviews' take-home messages [45]. Identify attributes of the context in which the research included in a systematic review was conducted to inform assessments of the applicability of the review in other contexts [45]

Opportunities for training and education on systematic significance, appraisal) [30]

Teaching about

systematic reviews, integration educational curricula, mandatory education of research methods to researchers, consultation support in methodology support in methodology

profesional method,

professional methodologists
Replacing unfamiliar terms or

adding definitions to the

view [47]. Ensure SRs are

included in a one-stop-shop

that provides quality-appraised

reviews [45]. Add addition

local value to any type of

language that is locally

applicable and by engaging

in discussions about the

implications of reviews with

the health care managers and

policy-makers who could

potentially act on the reviews

take-home messages [45]

Provide section on the relevance

of the evidence and the i

ntervention for low and middle

ne countries (LMICs) [47]

SRs are included in a

one-stop-shop that provides systematic review by using
Collaborative creation of knowledge in a format that is easy to view and

comprehensible and allows fast and easy referencing [49]

Involvement of librarians and health information specialists as a solution to lack of database access, establishment of a national portal for expanding access [51]

nvolvement in an advisory role by policy makers on research teams (i.e. involved research questions, assisted with dissemination) [42] 
Table 3 Facilitators to use of systematic reviews by policy makers and health care managers (Continued)

Relevance to policy

decisions [31]

Reassurance that no

reviews have been

missed [52]
Perception that systematic

reviews would overcom

the barrier of not having

enough time to use research

evidence [23]
Make the user-friendly "front end"

of systematic reviews available

through an online database

that could be searched using

keywords that make sense to

health care managers and policy-

makers and that is linked to the

full reviews when they

available through other sources

such as The Cochrane Library [45]

Replacing unfamiliar terms or

adding definitions to the

review [47]

Use of stories to help integration

come alive for participants so

they could see how it lives

operationally [49]. Provide section

on the relevance of the evidence

and the intervention for low and

middle income countries (LMICs)

[47]. Replacing unfamiliar terms

or adding definitions to the

re view [47]

Make the user-friendly "front end"

of systematic reviews available

through an online database that

could be searched using

keywords that make sense to

health care managers and policy

makers and that is linked to the

full reviews when they are

available through other sources,

such as The Cochrane Library [45]

Provide section on the relevance

of the evidence and the

intervention for low and middle

income countries (LMICS) [47]

Use of stories to help integration

come alive for participants so

they could see how it lives

operationally [49]. Make the

user-friendly "front end" of

systematic reviews available

through an online database that

could be searched using keywords

that make sense to health care

that is linked to the full revews

that is linked to the full reviews

when they are available through

Cochrane Library [45]

Use of less dense and more

accessible articles [49]. Use of
Position of end user within

organisation/system: programm

manager vs. director vs. medical

officer differed in uptake of

SRs [22]

Value the organisation placed on using research evidence for decision-making [23]

Having direct access to online database searching [23]

Existence of mechanisms to facilitate transfer of new

information in health unit [23]

Reallocate funding away from single study knowledge transfer 
Table 3 Facilitators to use of systematic reviews by policy makers and health care managers (Continued)

stories to help integration come

alive for participants so they

could see how it lives

Removing jargon and using

language that is locally applicable,

engage in discussion about the

potential implications of the

review [45]. It must be packaged

to incite and persuade, "to

translate the evidence into

something that is understandable

by the average legislator, average

citizen" [44]. Concrete

recommendations for practice [31]

It must be packaged to incite and persuade, "to translate the

evidence into something that is

understandable by the average

Use of familiar, non-jargon

language recommended [47].

Removing jargon and using

language that is locally applicable,

engage in discussion applicable,

potalial implications of the

review [45]

Reassurance that no reviews

have been missed [52]. Use

of familiar, non-jargon

language recommended

[47]. Removing jargon and

using language that is

locally applicable, engage

in discussion about the

potential implications of

the review [45]

Easy to use [31]. Framing

the evidence in terms of

how they can implement

it (specifically as a list of

questions to be considered

when developing and

implementing an

integrated health system,

information about how to

engage stakeholders, build

relationships and communicate

appropriately across target

audiences) [49]. Reassurance

that no reviews have been

missed [52] strategies, fund rapid reviews,

more proactive knowledge

transfer, health care manager

Priority of and support for

systematic reviews [51]

Announce priorities to be addressed using SR [51]

Meeting requestors time constraints [52]

Consistency in follow-up of individuals using on-demand service to appraise and interpret reviews of research [52]

Researchers and policy makers generally found reviews

commissioned through evidence check to accurately reflect the

state of the evidence, implying

that the requirement for rigour

and comprehensiveness was not

unnecessarily compromised by

the rapid timeframe in which

the reviews were conducted. It

is likely that this is due to both

knowledge brokers' attempts to

assist in precisely defining the

focus and scope of reviews early

in the commissioning process, 
Table 3 Facilitators to use of systematic reviews by policy makers and health care managers (Continued)

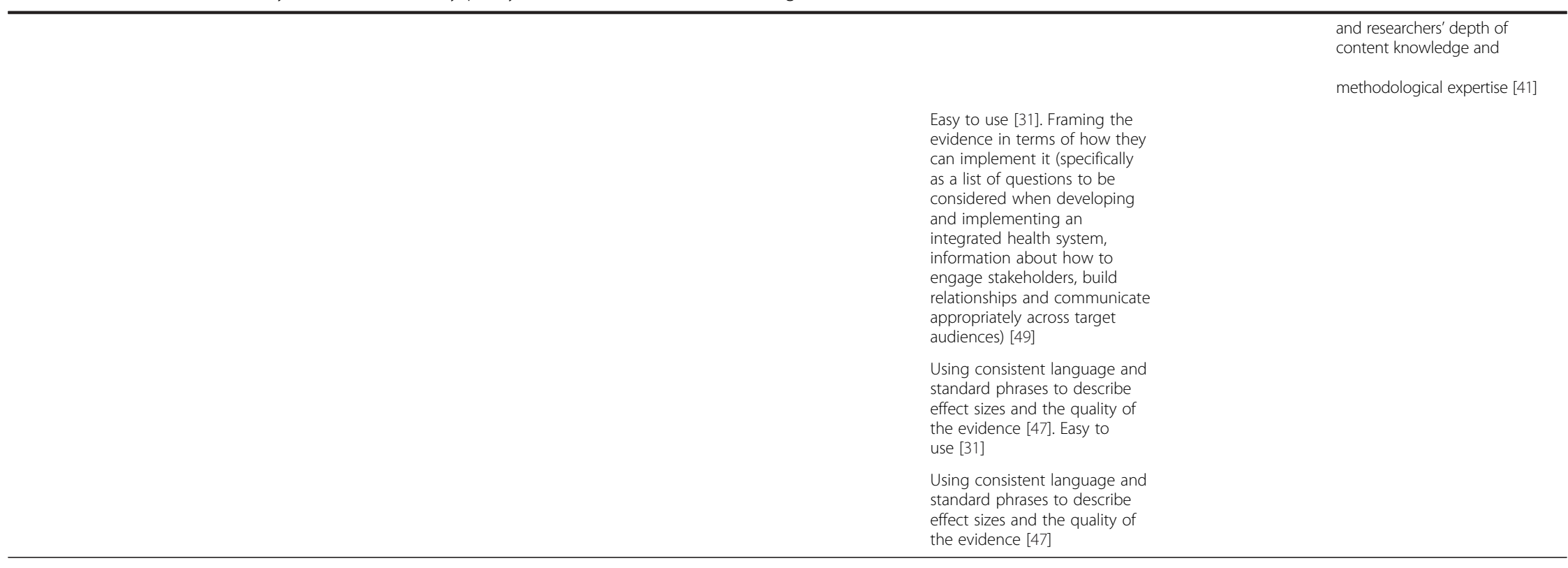




\section{Behaviour}

Extrinsic factors that were perceived to facilitate use included creating collaborations between policy makers and researchers whereby researchers could provide systematic reviews of relevance to policy makers in a timely fashion and facilitate their interpretation [23, 24, 42, 43]. This approach reflects a change in culture for researchers and policy makers/managers. In one of the intervention studies that were included, resources to implement the research and availability of the systematic review were identified as facilitators to using them in decision-making by public health officials [21].

\section{Format features to facilitate use of systematic reviews}

Several recommendations from policy makers and health care managers regarding formatting of systematic reviews to enhance uptake were identified (Table 4). Many participants suggested a one-page summary of the review including clear "take home" messages written in plain language, the publication date of the review, and sponsoring logos [47, 49]. Some participants recommended that the summary include sections on relevance, impact, and applicability for decision-makers [45, 47, 52]. They also recommended that the report for the full review should use a liberal amount of white space with bullet points (avoiding dense text) and simple tables (less than one page in length) and consider tailored versions with targeted key messages for relevant audiences [24]. Another suggestion was to frame the title of the systematic review as a question [47].

\section{Content features to facilitate use of systematic reviews}

A commonly requested feature amongst the studies was to frame the evidence in terms of policy application, including implications of implementation and potential outcomes (Table 5) [43, 47, 49]. Participants suggested that the methods details be minimised to focus on the critical elements and that the bulk of the report should focus on the results and interpretation [43, 44, 47]. Ways to make study quality of included studies easy for users to interpret, such as providing a graphical summary, were suggested $[44,47,52]$. Participants also asked that consistent approaches be used to report effect sizes of interventions throughout the review report.

\section{Conclusions}

We identified several determinants of the use of systematic reviews by policy makers and managers including factors influencing attitudes, knowledge, skills, and behaviours. For authors of systematic reviews, there are factors that are potentially modifiable and that may increase use of systematic reviews including features affecting format and content. From a format perspective, review authors can consider providing a one-page summary with key messages including importance of the topic, key results, and implications for decision-makers. This summary should be clearly written and concise. Similarly, the report for the full review should use white space, avoid dense text, and try to limit tables to one page. With regard to content of the reviews, the methods should be concise and the results should provide an easy to interpret summary of the risk of bias of individual studies, keeping in mind that the audience may have limited skills in appraising the evidence and limited time to do so. The use of a graphical display of the risk of bias, such as the figure advocated by the Cochrane Collaboration [53] is something review authors should consider using. The discussion should include the relevance of the results to decision-makers and factors important for contextualising the evidence. Systematic reviews should include consideration of what factors influence contextualisation of the evidence. To make knowledge more useful to the local context, commissioners of reviews such as policy makers frequently undertake processes to contextualise evidence [54], and if guidance on this can be provided by researchers, this may facilitate the process. For example, if information is available on how the evidence might be useful in resource constrained circumstances versus higher income settings, this should be provided in a systematic review. To make knowledge more useful to the local context, commissioners of reviews, such as policy makers, frequently undertake processes to contextualise evidence [54], and if guidance on this can be provided by researchers, this may facilitate their efforts. It was also suggested that the messages be tailored to different audiences, reflecting their needs. For example, the summary and report that is sent to policy makers would be different from the one sent to health care managers. These formatting suggestions should also be considered by journal editors and publishers to consider enhancing use of reviews. Of particular importance is the topic addressed by the systematic review as several studies raised the concern that the topics often were not perceived to be relevant by policy makers and managers. As such, it was suggested that a different approach be undertaken to conduct reviews whereby partnerships between researchers and decision-makers are created to ensure that the questions the reviews are tackling are relevant to the decision-makers. This approach requires a change in the organisational culture within health care and research, although there are numerous examples of successful partnerships like these $[4,5,55,56]$.

Several factors were perceived to influence use of systematic reviews that are extrinsic to the review, including a lack of motivation to use them, lack of awareness, and lack of skills to seek, appraise, and interpret systematic reviews. Tackling these challenges could also be addressed by developing partnerships between researchers and decisionmakers, such as a train the trainer approach whereby systematic reviewers work with decision-makers to build 
Table 4 Formatting features of systematic reviews to enhance uptake

\begin{tabular}{ll}
\hline Summary & Dissemination of SRs \\
\hline $\begin{array}{l}\text { Summary statement [30] } \\
\text { 1-page summaries in plain language [49] }\end{array}$ & $\begin{array}{l}\text { Share material on a website }[24,43] \\
\text { Provide tailored, targeted messages for } \\
\text { relevant audiences [24] }\end{array}$ \\
$\begin{array}{l}\text { Abbreviated format of research evidence, } \\
\text { such as an executive summary, would be }\end{array}$ & $\begin{array}{l}\text { Electronic communication channels are } \\
\text { preferable (1 to 2 pages long ) [43] }\end{array}$ \\
$\begin{array}{l}\text { Expectations of short, clear summary [47] } \\
\text { Newsletters containing summaries of }\end{array}$ \\
& $\begin{array}{l}\text { current research developed and directly } \\
\text { emailed to managers [43] }\end{array}$
\end{tabular}

Boxes placed throughout the summaries [47]

Summary of findings tables [47]

1-page summaries with references, so the reader is able to investigate further, and case studies [49]

Layout, presentation, setup
Graded format with key messages [47]
Recipe type guidance, the information
indicates this, this, and this [52]
Title framed as a question [47]

Reformatting the text to make it easier to pick out important parts [47]

\section{Chart on first page describing what review is about [47] \\ A modified academic abstract (relevance and description of review characteristics including the impact, applicability to setting, costs, or other considerations and need for no further evaluation) [47]}

Active delivery of information (as opposed to access to online registry) [24]
Preference for less dense, more accessible literature [49]

Wanted a shorter, clearer presentation [47]

A bullet point evaluation or rating system of study design quality so that for those of us who do not make our living doing that, we do not have to read a half dozen pages to ferret it out [44]

Develop a more user-friendly "front end" for potentially relevant systematic reviews (e.g. 1 page of take-home messages and a 3-page executive summary) to facilitate rapid

assessments of the relevance of a review by health care managers and policy makers and, when the review is deemed highly relevant, more graded entry into the full details of the review [45]

Well written and concise [47]

Limiting the number of tables and not letting them break across pages [47]

Simplifying the text and tables and ensuring that the results in the text matched those in the tables [47]

Moving partner logos and the summary publication date to the front page [47] capacity in either conducting reviews or interpreting their results within their organisation. If researchers can provide useful systematic reviews and illustrate how they can be used in a timely fashion to inform decision-making, this could provide motivation for continued use. Similarly, strategies to enhance awareness of reviews could be enhanced by these partnerships. Participants also raised the concern that using a systematic review to guide decision-making led to a perceived lack of autonomy in decision-making. This concern has been raised by clinicians for many years in relation to the practice of evidence-based health care, reflecting the issue that using evidence implies a "cookbook" approach to decision-making [57]. It highlights a misunderstanding around the appropriate use of evidence, whereby the practice of evidence-based health care requires integration of evidence, expertise, and values and circumstances [58].

Our results are consistent with systematic reviews of barriers [29] and facilitators [27] to use of systematic reviews by any decision-maker. These same authors also recently published a systematic review of interventions to increase use of systematic reviews [25]. Oliver and colleagues also published a review of barriers and facilitators to use of evidence by policy makers; however, their review was not limited to use of systematic reviews [59]. Search dates for all of these 
Table $\mathbf{5}$ Content features of systematic review that may increase their use

\begin{tabular}{|c|c|c|}
\hline Decision-making focus & Easy to understand & Details on included studies \\
\hline $\begin{array}{l}\text { Address relevant policy questions not academic } \\
\text { or business focused questions [44] }\end{array}$ & $\begin{array}{l}\text { Information about the information or meta- } \\
\text { information that tells you what to expect [47] }\end{array}$ & $\begin{array}{l}\text { Provide rating scale for quality of study } \\
\text { design [44] }\end{array}$ \\
\hline $\begin{array}{l}\text { Clearly articulate the implications of the findings } \\
\text { to public health practice and policy [43] }\end{array}$ & $\begin{array}{l}\text { Include content that was focused on key } \\
\text { findings or the "bottom line" from the study [43] }\end{array}$ & $\begin{array}{l}\text { Include section on the relevance of the } \\
\text { evidence and the intervention for low and } \\
\text { middle income countries (LMICs) [47] }\end{array}$ \\
\hline $\begin{array}{l}\text { Provide potential short- and long-term } \\
\text { outcomes expected as a result of implementing } \\
\text { the research findings into practice [43] }\end{array}$ & $\begin{array}{l}\text { Provide references to more detailed findings } \\
\text { so the reader is able to investigate further if } \\
\text { needed [49] }\end{array}$ & $\begin{array}{l}\text { Include table describing the characteristics } \\
\text { of the reviews [47] }\end{array}$ \\
\hline $\begin{array}{l}\text { Policy makers expect content lying outside the } \\
\text { scope of a review: recommendations, outcome } \\
\text { measurements not usually included in a review, } \\
\text { detailed information about local applicability or } \\
\text { costs, and a broader framing of the research } \\
\text { enquiry [47] }\end{array}$ & $\begin{array}{l}\text { Lack features that would make them easier for } \\
\text { government officials to evaluate. For example, } \\
\text { the quality of studies is often difficult for non- } \\
\text { experts to interpret because the explanation of } \\
\text { research methods is long and complicated [44] }\end{array}$ & $\begin{array}{l}\text { Include critical appraisal of included } \\
\text { studies [52] }\end{array}$ \\
\hline \multirow{6}{*}{$\begin{array}{l}\text { Frame the evidence in terms of how they } \\
\text { can implement it (specifically as a list of questions } \\
\text { to be considered when developing and } \\
\text { implementing an integrated health system } \\
\text { (which was topic of the review in this study), } \\
\text { information about how to engage stakeholders, } \\
\text { build relationships, and communicate } \\
\text { appropriately across target audiences) [49] }\end{array}$} & $\begin{array}{l}\text { Replace the section for references with a section } \\
\text { for "additional information": information that } \\
\text { was helpful for understanding the problem, that } \\
\text { provided details about the interventions, or that } \\
\text { put the results of the review in a broader } \\
\text { context [47] }\end{array}$ & $\begin{array}{l}\text { Include bullet point evaluation or rating } \\
\text { system of study design quality so that "for } \\
\text { those of us who don't make our living doing } \\
\text { that, we do not have to read a half dozen } \\
\text { pages to ferret it out" [44] }\end{array}$ \\
\hline & $\begin{array}{l}\text { It must be packaged to incite and persuade, } \\
\text { "to translate the evidence into something that } \\
\text { is understandable by the average legislator, } \\
\text { average citizen" [44] }\end{array}$ & \multirow[t]{5}{*}{$\begin{array}{l}\text { Provide table describing the characteristics } \\
\text { of the reviews: makes clear what the review } \\
\text { was looking for [47] }\end{array}$} \\
\hline & References are clear [47] & \\
\hline & Use familiar, non-jargon language [47] & \\
\hline & $\begin{array}{l}\text { Use consistent language and standard phrases } \\
\text { to describe effect sizes and the quality of the } \\
\text { evidence [47] }\end{array}$ & \\
\hline & Limit the discussion of methods [43] & \\
\hline
\end{tabular}

systematic reviews were between 2010 and 2012, while ours was extended to 2014. We found an additional six to nine studies not included in these reviews. Moreover, our review focused on factors (and categorised them) including format and content of the review. Our intent is to use the results of this review to inform the development of a template for providing results of systematic reviews to decision-makers and as such, we wanted to extend the findings of other reviews to include both intrinsic and extrinsic factors. Because of this focus, we did not include use of other types of research evidence beyond systematic reviews (e.g. results of single studies). Of note, we identified no additional studies reporting interventions to increase use of systematic reviews.

There are several limitations to our scoping review. First, it is a scoping review because we wanted to map the literature to inform future research on formatting systematic reviews and to provide guidance for authors of systematic reviews. As such, we did not perform risk of bias assessment on individual studies [32]. Second, most of the studies that were included in our scoping review were small qualitative studies and thus their results may not be generalizable. However, studies from a broad range of countries were included in our review, and the results are consistent across studies and previous reviews. Third, the literature search on this topic is limited by poor indexing of the primary studies in this area. To overcome this, our comprehensive search of the databases was supplemented by a grey literature search.

This review represents the first phase of a multiphase project with is being conducted in partnership with decision-makers from four provinces in Canada. The next phases include completing a survey of perceptions of barriers and facilitators to use of systematic reviews by policy makers and health care managers in these provinces; integrating the survey and review results to develop a format for systematic reviews and test its usability using heuristic and individual usability testing; and conducting a randomised trial to assess a traditional systematic review format compared with the new format on the ability of health care managers and policy makers to understand the 
evidence in the review and apply it to a relevant health care decision-making scenario. We have done similar work to create a format for clinicians and found that it influences their ability to apply the evidence from a systematic review to a clinical scenario [20, 60-64].

In summary, we identified common themes across a variety of studies that explored factors influencing use of systematic reviews by policy makers and managers. Useful information has been identified for authors of systematic reviews to inform their preparation of reviews including providing one-page summaries with key messages, tailored to the relevant audience. Moreover, partnerships between researchers and policy makers/managers to facilitate conduct and use of systematic reviews should be considered to enhance relevance of reviews and thereby influence uptake. Finally, these strategies should be rigorously evaluated to determine impact on reviews.

\section{Additional files}

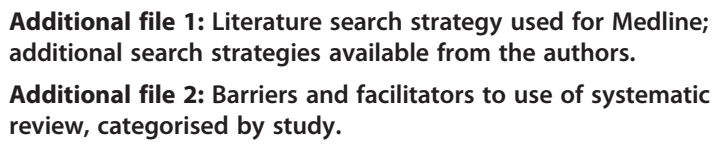

\section{Competing interests}

SES is an associate editor of Implementation Science but was not involved with the peer review process or decision to publish this paper. The rest of the authors have no competing interests to declare.

\section{Authors' contributions}

ACT conceived the study, screened citations and full-text articles, analysed and interpreted the data, and wrote the sections of the manuscript. RC and ST coordinated the study, screened the citations and full-text articles, abstracted the data, developed qualitative analysis, cleaned, coded and analysed the data, and edited the manuscript. SM, SES, and MK screened the citations and full-text articles, abstracted the data, and edited the manuscript. $\mathrm{BH}, \mathrm{MO}, \mathrm{MH}$, and SS conceived the study and conceptualised and edited the manuscript. LP conceived the study, developed the literature search, and conceptualised and edited the manuscript. SES conceived the study, analysed and interpreted the data, and wrote and edited the manuscript. All authors read and approved the final manuscripts.

\section{Acknowledgements}

ACT is funded by a CIHR-DSEN New investigator Award, and SES is funded by a Tier 1 Canada Research Chair. The authors thank Kelly Mrklas for screening some of the citations for inclusion, Dr. Monika Kastner for providing feedback on the pilot-test, Becky Skidmore for peer-reviewing and updating our search strategy, Ana Guzman for formatting the paper, and Alissa Epworth for obtaining the full-text articles.

\section{Author details}

${ }^{1}$ Knowledge Translation Program, Li Ka Shing Knowledge Institute, St. Michael's Hospital, 209 Victoria Street, East Building, Toronto, ON M5B 1W8, Canada. ${ }^{2}$ Epidemiology Division, Dalla Lana School of Public Health, University of Toronto, 155 College Street, Toronto, ON M5T 3M7, Canada. ${ }^{3}$ Department of Mechanical and Industrial Engineering, University of Toronto, 5 King's College Road, Toronto, ON M5S 3G8, Canada. ${ }^{4}$ Departments of Medicine and Community Health Sciences, University of Calgary, TRW Building, 3rd Floor, 3280 Hospital Drive NW, Calgary, AB T2N 4Z6, Canada. ${ }^{5}$ Département de science politique, Pavillon Charles-De Koninck, Université Laval, Quebec City, Canada. IInstitute of Health Policy, Management and
}

Evaluation, University of Toronto, Health Sciences Building, 155 College Street, Suite 425, Toronto, ON M5T 3M6, Canada. ${ }^{7}$ Research, Evaluation, and Analysis Branch, Ontario Ministry of Health and Long-Term Care, 80 Grosvenor Street, Toronto, ON M7A 1R3, Canada. ${ }^{8}$ Nuffield Department of Population Health, University of Oxford, Richard Doll Building, Old Rd Campus, Headington, Oxford, Oxfordshire OX3 7LF, UK. ${ }^{9}$ Department of Geriatric Medicine, University of Toronto, 27 Kings College Circle, Toronto, ON M5S 1A1, Canada.

Received: 1 August 2015 Accepted: 6 January 2016

Published online: 12 January 2016

\section{References}

1. Cook DJ, Mulrow CD, Haynes RB. Systematic reviews: synthesis of best evidence for clinical decisions. Ann Intern Med. 1997;126(5):376-80.

2. Antman EM, Lau J, Kupelnick B, Mosteller F, Chalmers TC. A comparison of results of meta-analyses of randomized control trials and recommendations of clinical experts. Treatments for myocardial infarction. JAMA. 1992;268(2):240-8.

3. Grimshaw JM, Santesso N, Cumpston M, Mayhew A, McGowan J. Knowledge for knowledge translation: the role of the Cochrane Collaboration. J Contin Educ Health Prof. 2006;26(1):55-62. doi:10.1002/chp.51.

4. Tricco AC, Soobiah C, Blondal E, Veroniki AA, Khan PA, Vafaei A, et al. Comparative safety of serotonin (5-HT3) receptor antagonists in patients undergoing surgery: a systematic review and network meta-analysis. BMC Med. 2015;13:142. doi:10.1186/s12916-015-0379-3.

5. Tricco AC, Soobiah C, Blondal E, Veroniki AA, Khan PA, Vafaei A, et al. Comparative efficacy of serotonin (5-HT3) receptor antagonists in patients undergoing surgery: a systematic review and network meta-analysis. BMC Med. 2015;13:136. doi:10.1186/s12916-015-0371-y.

6. Graham ID, Logan J, Harrison MB, Straus SE, Tetroe J, Caswell W, et al. Lost in knowledge translation: time for a map? J Contin Educ Health Prof. 2006; 26(1):13-24. doi:10.1002/chp.47.

7. J. L. Knowledge utilization. What is it? Knowledge: creation, diffusion, utilization. 1980;1:421-42.

8. Dunn WN. Measuring knowledge use. Knowledge: Creation, diffusion, utilization. 1983;5:120-33.

9. CH W. The many meanings of research utilization. Public Administration Rev. 1979:426-31.

10. Beyer JM, Trice HM. The utilization process: a conceptual framework and synthesis of empirical findings. Admin Sci. 1982;27:591-622.

11. Estabrooks CA. The conceptual structure of research utilization. Res Nurs Health. 1999;22:203-16.

12. Straus S, Tetroe J, Graham I. Knowledge translation in health care. Oxford: Wiley Blackwell, BMJ Books; 2013.

13. Oliver K, Lorenc T, Innvaer S. New directions in evidence-based policy research: a critical analysis of the literature. Health Res Policy Syst. 2014;12: 34. doi:10.1186/1478-4505-12-34.

14. Lavis JN, Ross SE, Hurley JE, Hohenadel JM, Stoddart GL, Woodward CA, et al. Examining the role of health services research in public policymaking. Milbank Q. 2002;80(1):125-54.

15. Oxman $A D$, Lavis $J N$, Fretheim A. Use of evidence in $W H O$ recommendations. Lancet. 2007;369(9576):1883-9. doi:10.1016/50140-6736(07)60675-8.

16. Grol R. Successes and failures in the implementation of evidence-based guidelines for clinical practice. Med Care. 2001;39(8 Suppl 2):|146-54.

17. Madon T, Hofman KJ, Kupfer L, Glass RI. Public health. Implementation science. Science. 2007;318(5857):1728-9. doi:10.1126/science.1150009.

18. Canadian Agency for Drugs and Technologies in Health. Systematic review of use of blood glucose test strips for the management of diabetes mellitus. 2009. https://www.cadth.ca/media/pdf/BGTS_SR_Report_of_Clinical_ Outcomes.pdf. Accessed 10 Jan 2016.

19. Ontario Drug Policy Research Network. Self-monitoring of blood glucose: patterns, costs and potential cost reduction associated with reduced testing. 2009. http://www.odprn.ca/research/self-monitoring-of-bloodglucose/ Accessed 10 Jan 2016.

20. Perrier L, Mrklas K, Lavis JN, Straus SE. Interventions encouraging the use of systematic reviews by health policymakers and managers: a systematic review. Implement Sci. 2011;6:43. doi:10.1186/1748-5908-6-43.

21. Ciliska D, Hayward S, Dobbins M, Brunton G, Underwood J. Transferring public-health nursing research to health-system planning: assessing the relevance and accessibility of systematic reviews. Can J Nurs Res. 1999;31 (1):23-36. 
22. Dobbins M, Cockerill R, Barnsley J. Factors affecting the utilization of systematic reviews. A study of public health decision makers. Int J Technol Assess Health Care. 2001;17(2):203-14.

23. Dobbins $M$, Cockerill $R$, Barnsley J, Ciliska D. Factors of the innovation, organization, environment, and individual that predict the influence five systematic reviews had on public health decisions. Int J Technol Assess Health Care. 2001;17(4):467-78.

24. Dobbins M, Hanna SE, Ciliska D, Manske S, Cameron R, Mercer SL, et al. A randomized controlled trial evaluating the impact of knowledge translation and exchange strategies. Implement Sci. 2009;4:61. doi:10.1186/1748-5908-4-61.

25. Wallace J, Byrne C, Clarke M. Improving the uptake of systematic reviews: a systematic review of intervention effectiveness and relevance. BMJ Open. 2014;4(10). doi:10.1136/bmjopen-2014-005834.

26. Murthy L, Shepperd S, Clarke MJ, Garner SE, Lavis JN, Perrier L, et al. Interventions to improve the use of systematic reviews in decisionmaking by health system managers, policy makers and clinicians. Cochrane Database Syst Rev. 2012;9:CD009401. doi:10.1002/14651858. CD009401.pub2.

27. Wallace J, Byrne C, Clarke M. Making evidence more wanted: a systematic review of facilitators to enhance the uptake of evidence from systematic reviews and meta-analyses. Int J Evid Based Healthc. 2012;10(4):338-46. doi:10.1111/j.1744-1609.2012.00288.x.

28. Ellen ME, Leon G, Bouchard G, Ouimet M, Grimshaw JM, Lavis JN. Barriers, facilitators and views about next steps to implementing supports for evidence-informed decision-making in health systems: a qualitative study. Implement Sci. 2014;9:179. doi:10.1186/s13012-014-0179-8.

29. Wallace J, Nwosu B, Clarke M. Barriers to the uptake of evidence from systematic reviews and meta-analyses: a systematic review of decision makers' perceptions. BMJ Open. 2012;2(5). doi:10.1136/bmjopen-2012-001220.

30. Dobbins M, DeCorby K, Twiddy T. A knowledge transfer strategy for public health decision makers. Worldviews Evid Based Nurs. 2004;1(2):120-8. doi:10.1111/j.1741-6787.2004.t01-1-04009.x.

31. Dobbins $\mathrm{M}$, Thomas $\mathrm{H}$, O'Brien MA, Duggan M. Use of systematic reviews in the development of new provincial public health policies in Ontario. Int J Technol Assess Health Care. 2004:20(4):399-404.

32. Arksey H, O'Malley L. Scoping studies: towards a methodological framework. Int J Soc Res Methodol. 2005:8(1):19-32. doi:10.1080/1364557032000119616.

33. Peters MD, Godfrey CM, Khalil H, Mclnerney P, Parker D, Soares CB. Guidance for conducting systematic scoping reviews. Int J Evid Based Healthc. 2015. doi:10.1097/xeb.0000000000000050.

34. Moher D, Liberati A, Tetzlaff J, Altman DG. Preferred reporting items for systematic reviews and meta-analyses: the PRISMA statement. BMJ. 2009; 339:b2535. doi:10.1136/bmj.b2535

35. Synthesi.SR. KT Program, Li Ka Shing Knowledge Institute of St. Michael's Hospital., Toronto, Ontario, Canada. 2014.

36. Cabana MD, Rand CS, Powe NR, Wu AW, Wilson MH, Abboud PA, et al. Why don't physicians follow clinical practice guidelines? A framework for improvement. JAMA. 1999;282(15):1458-65.

37. NVivo qualitative data analysis software; QSR International Pty Ltd. Version 10,2012

38. Albert MA, Fretheim A, Maiga D. Factors influencing the utilization of research findings by health policy-makers in a developing country: the selection of Mali's essential medicines. Health Res Policy Syst. 2007;5:2. doi:10.1186/1478-4505-5-2.

39. Armstrong R, Pettman T, Burford B, Doyle J, Waters E. Tracking and understanding the utility of Cochrane reviews for public health decisionmaking. J Public Health (Oxf). 2012;34(2):309-13. doi:10.1093/pubmed/ fds038.

40. Atack L, Gignac $P$, Anderson M. Getting the right information to the table: using technology to support evidence-based decision making. Healthc Manage Forum. 2010;23(4):164-8.

41. Campbell D, Donald B, Moore G, Frew D. Evidence check: knowledge brokering to commission research reviews for policy. Evid Policy. 2011;7(1): 97-107. doi:10.1332/174426411X553034.

42. Campbell DM, Redman S, Jorm L, Cooke M, Zwi AB, Rychetnik L. Increasing the use of evidence in health policy: practice and views of policy makers and researchers. Aust New Zealand Health Policy. 2009;6:21. doi:10.1186/ 1743-8462-6-21.

43. Dobbins M, Jack S, Thomas H, Kothari A. Public health decision-makers' informational needs and preferences for receiving research evidence.
Worldviews Evid Based Nurs. 2007;4(3):156-63. doi:10.1111/j.1741-6787.2007. 00089.x.

44. Jewell CJ, Bero LA. "Developing good taste in evidence": facilitators of and hindrances to evidence-informed health policymaking in state government. Milbank Q. 2008;86(2):177-208. doi:10.1111/j.1468-0009.2008.00519.x.

45. Lavis J, Davies H, Oxman A, Denis JL, Golden-Biddle K, Ferlie E. Towards systematic reviews that inform health care management and policy-making. J Health Serv Res Policy. 2005;10 Suppl 1:35-48. doi:10.1258/1355819054308549.

46. Ritter A. How do drug policy makers access research evidence? Int J Drug Policy. 2009;20(1):70-5. doi:10.1016/j.drugpo.2007.11.017.

47. Rosenbaum SE, Glenton C, Wiysonge CS, Abalos E, Mignini L, Young T, et al. Evidence summaries tailored to health policy-makers in low- and middle-income countries. Bull World Health Organ. 2011;89(1):54-61. doi:10.2471/blt.10.075481.

48. Shepperd S, Adams R, Hill A, Garner S, Dopson S. Challenges to using evidence from systematic reviews to stop ineffective practice: an interview study. J Health Serv Res Policy. 2013;18(3):160-6. doi:10.1177/1355819613480142.

49. Suter $\mathrm{E}$, Armitage GD. Use of a knowledge synthesis by decision makers and planners to facilitate system level integration in a large Canadian provincial health authority. Int J Integr Care. 2011;11:e011.

50. Vogel JP, Oxman AD, Glenton C, Rosenbaum S, Lewin S, Gulmezoglu AM, et al. Policymakers' and other stakeholders' perceptions of key considerations for health system decisions and the presentation of evidence to inform those considerations: an international survey. Health Res Policy Syst. 2013; 11:19. doi:10.1186/1478-4505-11-19.

51. Yousefi-Nooraie R, Rashidian A, Nedjat S, Majdzadeh R, Mortaz-Hedjri S, Etemadi $\mathrm{A}$, et al. Promoting development and use of systematic reviews in a developing country. J Eval Clin Pract. 2009;15(6):1029-34. doi:10.1111/j. 1365-2753.2009.01184.x

52. Packer $C$, Hyde $C$. Does providing timely access to and advice on existing reviews of research influence health authority purchasing? Public Health Med. 2000;2(1):20-4.

53. Higgins JP, Altman DG, Gotzsche PC, Juni P, Moher D, Oxman AD, et al. The Cochrane Collaboration's tool for assessing risk of bias in randomised trials. BMJ. 2011;343:d5928. doi:10.1136/bmj.d5928.

54. Wye L, Brangan E, Cameron A, Gabbay J, Klein J, Pope C. Health services and delivery research. Knowledge exchange in health-care commissioning: case studies of the use of commercial, not-for-profit and public sector agencies, 2011-14. Southampton: NIHR Journals Library; 2015

55. Uneke CJ, Ndukwe CD, Ezeoha AA, Uro-Chukwu HC, Ezeonu CT. Implementation of a health policy advisory committee as a knowledge translation platform: the Nigeria experience. Int J Health Policy Manag. 2015; 4(3):161-8. doi:10.15171/ijhpm.2015.21.

56. Lavis JN, Panisset U. EVIPNet Africa's first series of policy briefs to support evidence-informed policymaking. Int J Technol Assess Health Care. 2010; 26(02):229-32. doi:10.1017/S0266462310000206.

57. Straus SE, McAlister FA. Evidence-based medicine: a commentary on common criticisms. CMAJ. 2000;163(7):837-41.

58. Straus SERW, Glasziou P, Haynes RB. Evidence-based medicine: how to practice and teach EBM. 4th ed. London: Churchill Livingstone; 2010.

59. Oliver K, Innvar S, Lorenc T, Woodman J, Thomas J. A systematic review of barriers to and facilitators of the use of evidence by policymakers. BMC Health Services Research. 2014;14(1).

60. Perrier L, Persaud N, Thorpe KE, Straus SE. Using a systematic review in clinical decision making: a pilot parallel, randomized controlled trial. Implement Sci. 2015;10:118. doi:10.1186/s13012-015-0303-4.

61. Perrier L, Kealey MR, Straus SE. A usability study of two formats of a shortened systematic review for clinicians. BMJ Open. 2014;4(12):e005919. doi:10.1136/bmjopen-2014-005919.

62. Perrier L, Kealey MR, Straus SE. An iterative evaluation of two shortened systematic review formats for clinicians: a focus group study. JAMIA. 2014; 21(e2):e341-6. doi:10.1136/amiajnl-2014-002660.

63. Perrier L, Persaud N, Ko A, Kastner M, Grimshaw J, McKibbon KA, et al. Development of two shortened systematic review formats for clinicians. Implement Sci. 2013:8:68. doi:10.1186/1748-5908-8-68.

64. Perrier L, Mrklas K, Shepperd S, Dobbins M, McKibbon KA, Straus SE. Interventions encouraging the use of systematic reviews in clinical decision-making: a systematic review. J Gen Intern Med. 2011;26(4): 419-26. doi:10.1007/s11606-010-1506-7. 